\title{
Epidemiological and advanced therapeutic approaches to treatment of uveitis in pediatric rheumatic diseases: a systematic review and meta-analysis
}

\author{
Mohsen Jari ${ }^{1,2^{*}}$, Reza Shiari ${ }^{3}$, Omid Salehpour ${ }^{4}$ and Khosro Rahmani ${ }^{3}$
}

\begin{abstract}
Background: Despite the low prevalence of uveitis in pediatric rheumatic diseases, potential problems as well as high disease burden can complicate its management. In this review, we systematically assessed the epidemiological, etiological, and managerial aspects of uveitis in pediatric rheumatic diseases.

Methods: This current study was conducted in accordance with the established methods and the Preferred Reporting Items for Systematic Review and Meta-Analysis Protocols (PRISMA-P). We searched the manuscript databases, including Medline, Web of Knowledge, Google Scholar, Scopus, and Cochrane for all eligible studies in line with the considered keywords. We also conducted the statistical analysis using the Stata software.

Results: Considering studies focusing on uveitis in Juvenile Idiopathic Arthritis (JIA) yielded a pooled prevalence of 11.8\% (95\%Cl: 11.2 to 12.4\%) for uveitis following JIA. In this regard, the prevalence rate of uveitis related to Behçet's disease and Systemic Lupus Erythematosus (SLE( was estimated to be 15.0 and 0.8\%, respectively. The pooled response rate to Adalimumab and Infliximab was estimated to be $68.0 \%$ (95\%Cl: 65.4 to $70.6 \%$ ), $64.7 \%$ (95\%Cl: 59.8 to $69.3 \%$ ), respectively. The documents for the systematical assessment of other biological medications (e.g. Tocilizumab, Daclizumab and Rituximab) were inadequate; however, the mean response rate for these drugs was 59, 75 and 80\%, respectively. Our meta-analysis showed a pooled response rate of $40.0 \%(95 \% \mathrm{Cl}, 36.0 \%$ to 44.2$)$ to Methotrexate. Significant heterogeneity and significant diffusion bias were demonstrated by reviewing studies.

Conclusions: The pooled prevalence of uveitis in pediatric rheumatic diseases widely varied based on the underlying disease requiring more investigations in different subtypes of rheumatic diseases. The biologic medications, especially Adalimumab are the most effective treatments for uveitis in pediatric rheumatic diseases; however, a combination of the safe, available alternatives is preferred to achieve the most desirable treatment response.
\end{abstract}

Keywords: Rheumatology, Pediatric, Uveitis, Treatment, Prevalence

\section{Background}

Uveitis in pediatric rheumatic diseases is identified as an inflammatory event of the uvea of the iris, choroid, and retina. Although rheumatic diseases are partially common during childhood, the rheumatic disease-related uveitis is an

\footnotetext{
* Correspondence: mjari14@yahoo.com

'Department of Pediatric Rheumatology, Imam Hossein Children's Hospital. Isfahan University of Medical Sciences, Isfahan, Iran

${ }^{2}$ Child Growth and Development Research Center, Research Institute for Primordial prevention of non-communicable Disease, Isfahan University of Medical Sciences, Isfahan, Iran

Full list of author information is available at the end of the article
}

uncommon finding in young people accounting for approximately 5 to $10 \%$ of all individuals with uveitis $[1,2]$. Despite its low prevalence, potential complications of uveitis as well as high disease burden present the disease management as a considerable challenge. Although uveitis, due to rheumatic diseases, may be easily diagnosed, the effective treatments of this event remain limited owing to serious systemic side effects [3]. More importantly, delay of diagnosis and treatment may lead to irreversible consequences like severe vision loss [4]. In this review, we systematically

(c) The Author(s). 2020 Open Access This article is distributed under the terms of the Creative Commons Attribution 4.0 International License (http://creativecommons.org/licenses/by/4.0/), which permits unrestricted use, distribution, and 
assessed the epidemiological, etiological and managerial aspects of uveitis in pediatric rheumatic diseases.

\section{Materials and methods}

Search strategy: This study was conducted according to the previous established methods and in compliance with the Preferred Reporting Items for Systematic review and Meta-Analysis Protocols (PRISMA-P) [5]. The manuscript databases, including Medline, Web of Knowledge, Google Scholar, Scopus, and Cochrane were searched for any eligible studies in association with "Uveitis", "Rheumatology", and "pediatrics". The studies were restricted to those written in English. The inclusion criteria were the epidemiology, etiologies, and the treatments of uveitis in pediatric rheumatic diseases. The exclusion criteria were introduced as follows: a lack of clear and reproducible results, nonEnglish studies, lack of access to the full text manuscript, case reports, case series, and review papers.

Data abstraction and validity assessment: Data abstraction was independently performed by two un-blinded reviewers on the structure collection forms without divergences in data collection. The study quality was evaluated based on the following criteria: 1) the systematic review and meta-analysis based on the questions primarily described and formulated; 2) inclusion and exclusion criteria predefined in the studies as eligibility criteria; 3 ) searching the literature performed on a systematic and comprehensive approach; 4), the full texts of the article dually reviewed to minimize the bias 5) the quality of included studies independently rated by the reviewers for appraising internal validity 6) the comprehensive list of studies' characteristics and findings7) the list of publication and risk of bias8) the assessment of heterogeneity [6]. The present study aimed to determine the global prevalence, causes and new therapies of rheumatoid arthritis in children by determining the prevalence as well as the odds ratio in the relationship between the major risk factors and disease risk. Furthermore, the year of publishing, number of included patients, and the method of design were pointed.

Statistical analysis: Dichotomous variables are reported as proportions and percentages, and continuous variables as mean values. Binary outcomes from individual studies were to be combined with both Mantel-Hansel fixed effect models. The odds ratio (OR) and 95\% confidence interval (CI) were used as concise statistics to compare the dichotomous variables. Cochran's $\mathrm{Q}$ test was used to determine the statistical heterogeneity of this study. This test was complemented with the $\mathrm{I}^{2}$ statistic quantifying the proportion of total variation across studies due to heterogeneity rather than chance. A value of I2 of $0-25 \%$ indicates insignificant heterogeneity, 26-50\% low heterogeneity, 51-75\% moderate heterogeneity, and $76-100 \%$ high heterogeneity. The publication bias was assessed by the rank correlation test and it was confirmed by the funnel plot analysis. The reported values were two-tailed, and hypothesis testing results were considered statistically significant at $p=0.05$. Statistical analysis was conducted using the Stata software (version 13.1, Stata Corp, College Station, TX, USA).

\section{Results}

\section{Prevalence and other epidemiological aspects of uveitis} in pediatric rheumatic diseases

To assess different epidemiological aspects of uveitis in pediatric rheumatic diseases based on the applied keywords, 19 out of 128 studies focused on the different epidemiological aspects of uveitis in pediatric rheumatic diseases and 4 were excluded due to lack of adequate information, and 2 were excluded due to lack of full text, or review article in nature. Finally, 13 studies published between 1997 and 2017 met the endpoints that were analyzed [7-19] (Table 1).

In total, 11,875 patients were assessed indicating a higher rate of uveitis in female than in male children. The average age of the patients at the beginning of uveitis was 8.8 years. Of 13 patients focused uveitis in pediatric rheumatic diseases, most of them (11 out of 13 manuscripts) included children suffering Juvenile Idiopathic Arthritis (JIA), while Behçet's disease-related uveitis was assessed in one study and Systemic Lupus Erythematosus (SLE-related) uveitis in another. Initially considering studies focused on JIA-related uveitis yielded a pooled prevalence of $11.8 \%$ (95\%CI: 11.2 to 12.4\%) for uveitis following JIA (Fig. 1). In this regard, the prevalence rate of uveitis related to Behçet's disease and SLE was estimated to be 15.0 and $0.8 \%$, respectively. The main predictors of uveitis in children suffering from rheumatic diseases were female gender, age $<7$ years at the onset of JIA (particularly in girls), oligoarticular subtype of disease and positive antinuclear antibody (ANA) $>15 \mathrm{U} / \mathrm{ml}$. ANA is positive in 70 to $90 \%$ those with uveitis. In this regard, poly-articular RF-positive subtype of JIA was revealed to be protective of uveitis. Reviewing the literature showed a strong racial tendency to uveitis in pediatric rheumatic diseases, so that the possibility of JIA-related uveitis in caucasian white children was nearly twice as much as AfricanAmerican children. Regarding uveitis-related complications, the common complications encompassed band keratopathy (15.7 to $29 \%$ ), synechiae (27 to $33 \%$ ), cataract (8 to $31 \%$ ), macular edema (6 to $25 \%$ ), ocular hypertension/glaucoma (8 to $19 \%$ ), and macular fibrosis (4\%). Overall, complications of uveitis developed in 35.5 to $67 \%$ of children that one-third of them were present at diagnosis. Final visual acuity less than $20 / 50$ was found in 11 to $31 \%$ and less than $20 / 200$ in $12 \%$ of eyes, but blindness widely occurred from 0 to $17.5 \%$ in the affected children that was more common in African American children than in Caucasian children. The risk to vision is higher if JIA begins in the preschool years. To determine the overall prevalence of JIA-related uveitis, the statistical heterogeneity was significant with an 
Table 1 The details of the studies on the prevalence and determinants of uveitis

\begin{tabular}{|c|c|c|c|c|c|c|c|}
\hline Author, year & Number & $M / F$ & Age at onset & Rheumatic dis. & $\begin{array}{l}\text { Prevalence } \\
\text { of Uveitis }\end{array}$ & Predictors of uveitis & Complications of uveitis \\
\hline Nordal, 2017 [7] & 435 & $149 / 286$ & 5.5 & $J I A$ & $89(20.5)$ & $\begin{array}{l}\text { age }<7 \text { years at JIA } \\
\text { onset AHA }>15 \mathrm{U} / \mathrm{ml} \\
\text { ANA }\end{array}$ & \\
\hline Sardar, 2017 [8] & 102 & $10 / 102$ & 10.0 & Behçet's & $15(15.0)$ & & $\begin{array}{l}\text { synechiae, cataract, } \\
\text { and macular edema }\end{array}$ \\
\hline Kahwage, 2017 [9] & 852 & $1 / 7$ & 11.2 & CSLE & $7(0.8)$ & Fever, lymphadenopathy & \\
\hline Cecchin, 2017 [10] & 274 & $50 / 224$ & 11.5 & $J \mid A$ & $57(20.8)$ & Hypomobility & \\
\hline Angeles, 2015 [11] & 287 & $82 / 205$ & 6.5 & $J \mid A$ & $52(18.0)$ & $\begin{array}{l}\text { younger age oligoarticular } \\
\text { subtype }\end{array}$ & Blindness \\
\hline Angeles, 2013 [12] & 4983 & & 11.4 & $J \mid A$ & 459 (11.6) & $\begin{array}{l}\text { female sex early age } \\
\text { of arthritis onset, } \\
\text { oligoarticular subtype }\end{array}$ & \\
\hline Clarke, 2013 [13] & 79 & $42 / 37$ & 9.0 & $J \mid A$ & $18(22.8)$ & & \\
\hline Shen, 2013 [14] & 292 & $88 / 107$ & 9.5 & $J \mid A$ & $19(6.7)$ & & \\
\hline Reininga, 2008 [15] & 153 & & & $J \mathrm{~A}$ & $27(17.6)$ & & $\begin{array}{l}\text { Visual loss, glaucoma, cataract, } \\
\text { posterior synechiae, cystoid } \\
\text { macular oedema and papillitis }\end{array}$ \\
\hline Grassi, 2007 [16] & 309 & $65 / 179$ & 4.9 & $J \mid A$ & $62(20.1)$ & $\begin{array}{l}\text { early age of arthritis } \\
\text { onset ANA DRB1*11 }\end{array}$ & \\
\hline Heiligenhaus, 2005 [17] & 3271 & & & $J \mathrm{~A}$ & $392(12.0)$ & $\begin{array}{l}\text { early age of arthritis onset } \\
\text { female gender ANA }\end{array}$ & $\begin{array}{l}\text { band keratopathy, posterior } \\
\text { synechiae, cataract, glaucoma, } \\
\text { and macula oedema }\end{array}$ \\
\hline Chalom, 1997 [18] & 760 & & & $J \mid A$ & $74(9.3)$ & early age of arthritis onset & $\begin{array}{l}\text { synechiae, band keratopathy, } \\
\text { cataract, or glaucoma }\end{array}$ \\
\hline Akduman, 1997 [19] & 78 & & & $J \mathrm{~A}$ & $7(9.0)$ & & $\begin{array}{l}\text { Visual loss band keratopathy } \\
\text { and cataract }\end{array}$ \\
\hline
\end{tabular}

$\mathrm{I}^{2}$ of $93.771 \%(P<0.001)$ (Fig. 1). There was a significant publication bias as evidenced by either funnel plot asymmetry or the Egger test $(P=0.026)$.

Pathophysiology of uveitis in pediatric rheumatic diseases At the beginning of the last century, the eye manifestations of rheumatic diseases, especially in children with JIA had been well described. Since then, numerous cases of JIArelated uveitis have been reported. Formerly, many cases might have been missed in diagnosis, particularly asymptomatic patterns leading to high rates of visual loss; however, by advancing diagnostic approaches, this event is now rarely reported. The nature of rheumatic disease-related uveitis is mostly insidious at the onset and in some cases may be followed by a remitting course. Both eyes are mostly affected. In many cases, uveitis is nongranulomatous with a faint flare. In mild cases, Keratic precipitates can be seen in the inferior half of the corneal endothelium progressed to the anterior vitreous in severe cases with spreading inflammation to the posterior parts of the eye. Most changes have been identified to be linked to Human Leukocyte Antigen B27 (HLA B27) as one of the main markers for arthritis.

Naturally, uveitis is more commonly discovered in children with oligoarthritis and more rarely in systemic-onset arthritis. JIA-related uveitis more commonly occurs earlier in females than in males, a difference, which has not been exclusively explained. Although $90 \%$ of uveitis cases are revealed within the first 4 years of arthritis, it may sometimes occur in the first 7 years after onset of arthritis.

The pathogenesis of JIA and its associated uveitis is unknown. It is presumed to be autoimmune in nature. Genetically, histocompatibility allele profiles have been widely assessed, and higher expression of some HLA alleles such as DRB1*1104 andDRB1*01 was found in those with uveitis emphasizing the autoimmune nature of disease. Furthermore, the positivity of ANA in most cases also emphasizes this fact. Additionally, immune complex deposition has a potential place in the pathogenesis of uveitis, but the details of autoimmunity and specific autoantibodies in pathogenesis of uveitis are under investigation.

\section{Recent advances in the treatment of uveitis in pediatric rheumatic diseases}

Table 2 summarizes different medical therapeutic approaches to uveitis in pediatric rheumatic diseases. Formerly, two groups of drugs, including glucocorticoids and nonbiologic Disease-Modifying Anti Rheumatic Drugs (DMARDS), were widely used to improve uveitis; however, 


\begin{tabular}{|c|c|c|c|c|c|c|c|c|c|}
\hline \multicolumn{10}{|c|}{ Meta Analysis } \\
\hline \multirow[t]{2}{*}{ Study name } & \multirow[b]{2}{*}{$\begin{array}{c}\text { Event } \\
\text { rate }\end{array}$} & \multicolumn{3}{|c|}{ Statistics for each study } & \multirow[b]{2}{*}{ p-Value } & & \multicolumn{2}{|c|}{ Event rate and $95 \% \mathrm{Cl}$} & \\
\hline & & $\begin{array}{c}\text { Lower } \\
\text { limit }\end{array}$ & $\begin{array}{l}\text { Upper } \\
\text { limit }\end{array}$ & Z-Value & & & & & \\
\hline Nordal, 2017 & 0.205 & 0.169 & 0.245 & $11.424-$ & 0.000 & & & $=$ & 1 \\
\hline Sardar, 2017 & 0.147 & 0.091 & 0.230 & $6.288-$ & 0.000 & & & - & \\
\hline Kahwage, 2017 & 0.008 & 0.004 & 0.017 & $12.630-$ & 0.000 & & & & \\
\hline Cecchin, 2017 & 0.208 & 0.164 & 0.260 & $8.982-$ & 0.000 & & & $=$ & \\
\hline Angeles, 2015 & 0.181 & 0.141 & 0.230 & $9.842-$ & 0.000 & & & $=$ & \\
\hline Angeles, 2013 & 0.092 & 0.084 & 0.100 & 46.709- & 0.000 & & & & \\
\hline Clarke, 2013 & 0.228 & 0.149 & 0.333 & $4.550-$ & 0.000 & & & $\rightarrow$ & \\
\hline Shen, 2013 & 0.065 & 0.042 & 0.100 & $11.232-$ & 0.000 & & & $=$ & \\
\hline Reininga, 2008 & 0.176 & 0.124 & 0.245 & $7.264-$ & 0.000 & & & $=$ & \\
\hline Grassi, 2007 & 0.201 & 0.160 & 0.249 & $9.731-$ & 0.000 & & & $=$ & \\
\hline Heiligenhaus, 2005 & 0.120 & 0.109 & 0.131 & $37.037-$ & 0.000 & & & 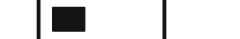 & \\
\hline Chalom, 1997 & 0.097 & 0.078 & 0.121 & 18.199- & 0.000 & & & - & \\
\hline \multirow[t]{4}{*}{ Akduman, 1997} & 0.090 & 0.043 & 0.176 & $5.848-$ & 0.000 & & & $=$ & \\
\hline & 0.118 & 0.112 & 0.124 & $67.288-$ & 0.000 & & & 1 & \\
\hline & & & & & & -1.00 & -0.50 & 0.00 & 1.00 \\
\hline & & & & & & & Favours A & Favours B & \\
\hline
\end{tabular}

Meta Analysis

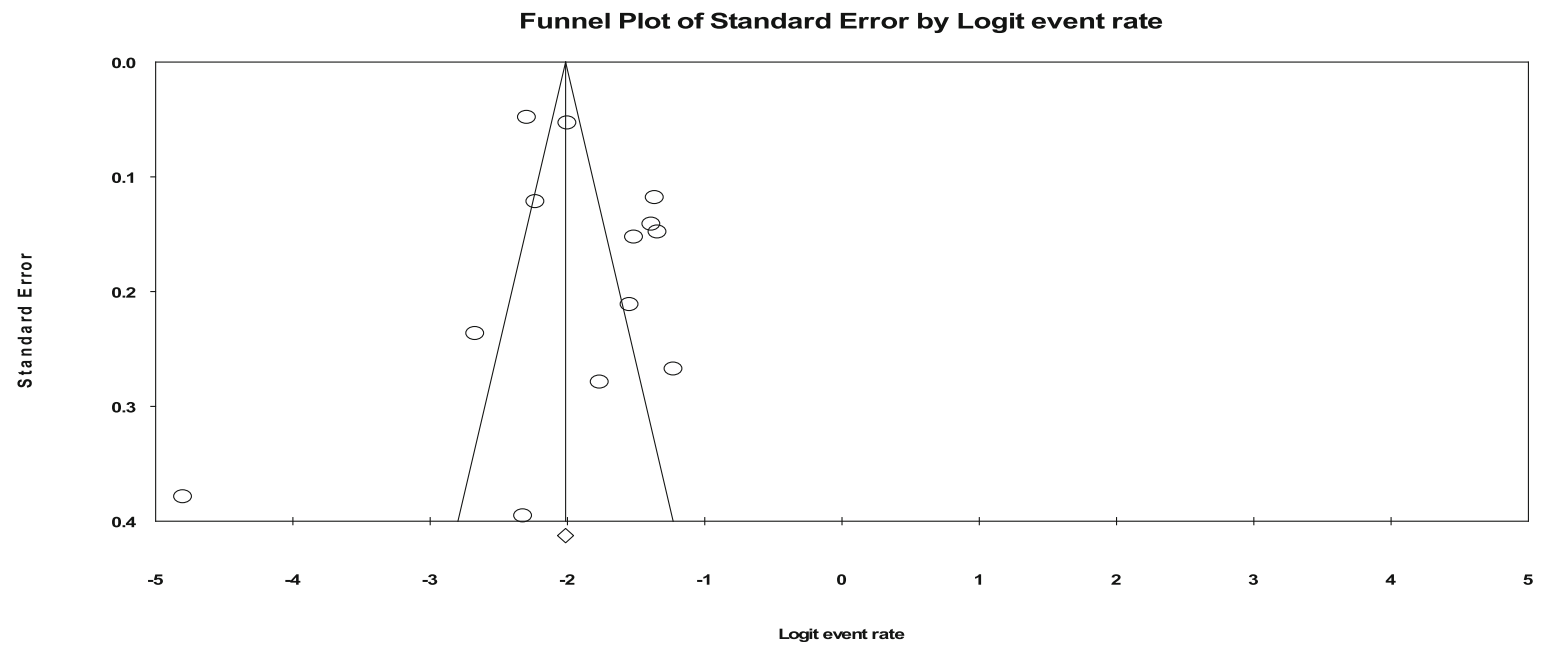

Fig. 1 Prevalence of JIA-related uveitis. Our meta-analyses yielded a pooled prevalence of 11.8\% (95\%Cl: 11.2 to 12.4\%) for uveitis following JIA. To determine overall prevalence of JIA-related uveitis, the statistical heterogeneity was significant with an $\mathrm{I}^{2}$ of $93.771 \%(P<0.001)$

by developing biological agents, these medications have been considered particularly. To evaluate the efficacy, response rates and complications of any old and novel drugs based on the applied keywords, of total 157 studies initially conducted, 42 studies published between 1998 and 2017 focused on different medications against uveitis (Table 2. At the end of document text file).
Of 42 studies, 34 focused on biological agents (Adalimumab in 14 studies, Infliximab in 10 studies, Etanercept in 5 studies, Tocilizumab in 3 studies, Rituximab in 1 study and Daclizumab in 1 study). In addition, Methotrexate as a common used DMARD for uveitis was assessed in 8 studies. Totally, the efficacy of Adalimumab was assessed in 1289 patients. The pooled response rate to Adalimumab 
Table 2 The details of the studies on the response to different therapeutic regimens

\begin{tabular}{|c|c|c|c|c|c|}
\hline Author, year & Type of study & Disease & Number & Medication & Response rate \\
\hline Correll, 2017 [20] & Review chart & $J \mathrm{~A}$ & 60 & Adalimumab & $80.0 \%$ \\
\hline Horneff, 2016 [21] & Review chart & $J \mid A$ & 236 & Adalimumab & $61.0 \%$ \\
\hline Castiblanco, 2016 [22] & Review chart & $J \mid A$ & 14 & Adalimumab & $77.0 \%$ \\
\hline Henderson, 2016 [23] & cohort study & $J \mathrm{~A}$ & 92 & Adalimumab & $68.0 \%$ \\
\hline Klotsche, 2016 [24] & cohort study & $J \mathrm{~A}$ & 320 & Adalimumab & $77.0 \%$ \\
\hline Schmeling, 2014 [25] & Review chart & $J \mathrm{~A}$ & 289 & Adalimumab & $63.4 \%$ \\
\hline García, 2013 [26] & Clinical trial & $J \mathrm{~A}$ & 39 & Adalimumab & $60.0 \%$ \\
\hline Lerman, 2013 [27] & Review chart & $J \mathrm{~A}$ & 56 & Adalimumab & $75.0 \%$ \\
\hline Simonini, 2013 [28] & Clinical trial & JIA, Behçet's & 14 & Adalimumab & $57.4 \%$ \\
\hline Zannin, 2013 [29] & Cohort Study & $J \mathrm{~A}$ & 108 & Adalimumab & $67.4 \%$ \\
\hline Trachana, 2011 [30] & Cohort Study & $J \mathrm{~A}$ & 9 & Adalimumab & $65.4 \%$ \\
\hline Tynjälä, 2008 [31] & Review chart & $J \mathrm{~A}$ & 20 & Adalimumab & $65.0 \%$ \\
\hline Gallagher, 2007 [32] & case series & $J \mathrm{~A}$ & 23 & Adalimumab & $77.0 \%$ \\
\hline Vazquez, 2006 [33] & Clinical trial & $J \mathrm{~A}$ & 9 & Adalimumab & $80.8 \%$ \\
\hline Sardar, 2017 [8] & Review chart & $J \mathrm{~A}$ & 56 & Infliximab & $80.0 \%$ \\
\hline Aeschlimann, 2017 [34] & Review chart & $J \mathrm{~A}$ & 52 & Infliximab & $60.0 \%$ \\
\hline Aeschlimann, 2014 [35] & Review chart & $J \mathrm{~A}$ & 82 & Infliximab & $57.0 \%$ \\
\hline Tambralli, 2013 [36] & Review chart & $J \mathrm{~A}$ & 95 & Infliximab & $74.1 \%$ \\
\hline Zannin, 2013 [29] & Review chart & $J \mathrm{~A}$ & 48 & Infliximab & $42.8 \%$ \\
\hline Tugal, 2008 [37] & Review chart & $J \mathrm{~A}$ & 20 & Infliximab & $80.0 \%$ \\
\hline Ardoin, 2007 [38] & Case series & $J \mathrm{~A}$ & 16 & Infliximab & $79.0 \%$ \\
\hline de Oliveira, 2007 [39] & Review chart & $J \mathrm{~A}$ & 30 & Infliximab & $70.0 \%$ \\
\hline Tynjälä, 2007 [40] & Review chart & $J \mathrm{~A}$ & 21 & Infliximab & $31.0 \%$ \\
\hline Rajaraman, 2006 [41] & Review chart & $J \mathrm{~A}$ & 6 & Infliximab & $100 \%$ \\
\hline Saeed, 2014 [42] & Review chart & $J \mathrm{~A}$ & 9 & Etanercept & $66.7 \%$ \\
\hline Foeldvari, 2007 [43] & Review chart & $J \mathrm{~A}$ & 34 & Etanercept & $70.0 \%$ \\
\hline Tynjälä, 2007 [40] & Review chart & $J \mathrm{~A}$ & 45 & Etanercept & $31.0 \%$ \\
\hline de Oliveira, 2007 [39] & Review chart & $J \mathrm{~A}$ & 9 & Etanercept & $70.0 \%$ \\
\hline Horneff, 2016 [21] & Review chart & $J \mathrm{~A}$ & 94 & Etanercept & $68.0 \%$ \\
\hline Quesada, 2017 [44] & Review chart & $J \mathrm{~A}$ & 89 & Tocilizumab & $46.0 \%$ \\
\hline Horneff, 2016 [21] & Review chart & $J \mathrm{~A}$ & 74 & Tocilizumab & $61.0 \%$ \\
\hline Tappeiner, 2016 [45] & Review chart & $J \mathrm{~A}$ & 17 & Tocilizumab & $58.8 \%$ \\
\hline Miserocchi, 2016 [46] & Review chart & $J \mathrm{~A}$ & 8 & Rituximab & $75.0 \%$ \\
\hline Gallagher, 2007 [32] & Review chart & $J \mathrm{~A}$ & 23 & Daclizumab & $80.0 \%$ \\
\hline Henderson, 2016 [23] & cohort study & $J \mathrm{~A}$ & 92 & Methotrexate & $76.0 \%$ \\
\hline Saeed, 2014 [42] & Review chart & $J \mathrm{~A}$ & 147 & Methotrexate & $34.0 \%$ \\
\hline Marvillet, 2009 [47] & Review chart & $J \mathrm{~A}$ & 75 & Methotrexate & $17.4 \%$ \\
\hline Papadopoulou, 2013 [48] & Review chart & $J \mathrm{~A}$ & 254 & Methotrexate & $33.9 \%$ \\
\hline Kalinina, 2011 [49] & Review chart & $J \mathrm{~A}$ & 22 & Methotrexate & $82.0 \%$ \\
\hline Heiligenhaus, 2007 [50] & Review chart & $J \mathrm{~A}$ & 31 & Methotrexate & $41.9 \%$ \\
\hline Shetty, 1999 [51] & Review chart & $J \mathrm{~A}$ & 4 & Methotrexate & $50.0 \%$ \\
\hline Weiss, 1998 [52] & Review chart & $J \mid A$ & 7 & Methotrexate & $85.7 \%$ \\
\hline
\end{tabular}


was estimated to be $68.0 \%$ (95\%CI: 65.4 to $70.6 \%$ ). The drug-related side effects were recorded in the wide range of 3 to $52 \%$, including non-ocular complications (e.g. autoimmune diseases, local pain, anemia, depression, abscess and even sepsis) and ocular complications (e.g. cataracts, and uveitis flares). However, they were mostly tolerable with the patients. In assessing the studies on the efficacy of Adalimumab, the statistical heterogeneity was significant with an $\mathrm{I}^{2}$ of $57.164 \%(P=008)$ (Fig. 2). There was no significant publication bias as evidenced by either funnel plot asymmetry or the Egger test $(P=0.576)$.

To determine the efficacy of Infliximab, 476 patients were examined for the medications leading to a pooled response rate of $64.7 \%$ (95\%CI: 59.8 to $69.3 \%$ ). The most common side effects of the medications were the reactivation of uveitis and infusion reaction in approximately

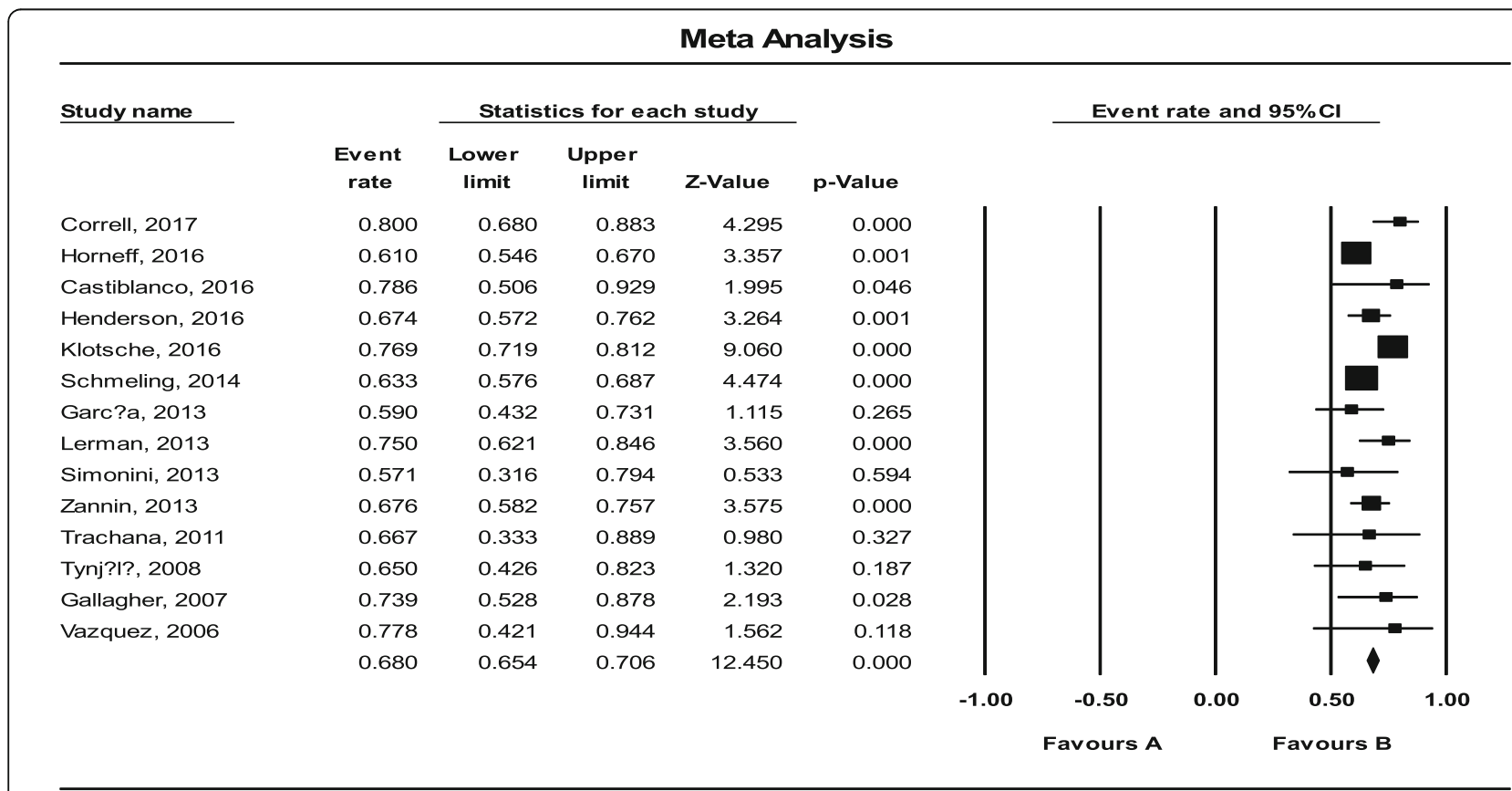

Meta Analysis

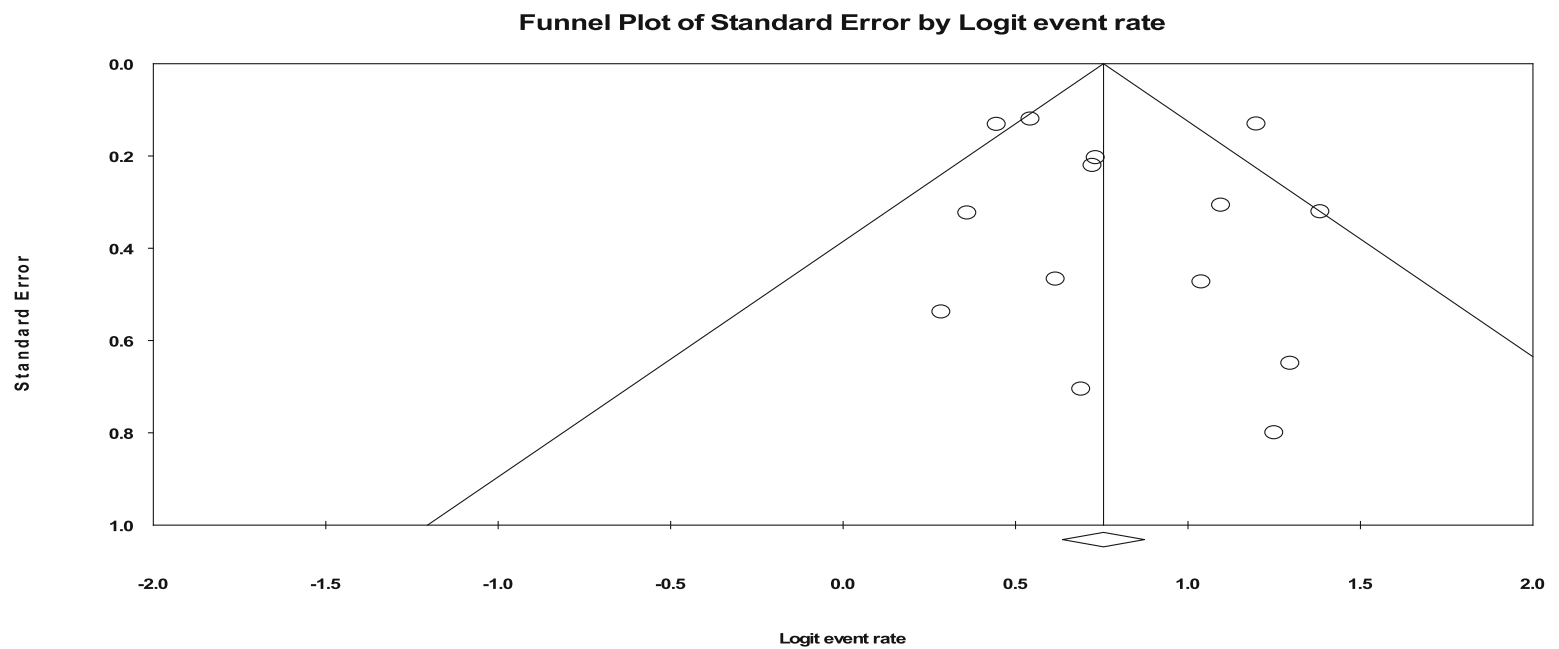

Fig. 2 The efficacy of Adalimumab to treat JIA-related uveitis. The efficacy of Adalimumab was assessed in 1289 patients. The pooled response rate to Adalimumab was estimated to be $68.0 \%$ (95\% Cl: 65.4 to $70.6 \%$ ). Assessment of the studies on the efficacy of Adalimumab indicated that the statistical heterogeneity was significant with an $I^{2}$ of $57.164 \%$ 
two-third of the patients, infectious events, vitreous hemorrhage, and systemic infections. In this regard, the statistical heterogeneity was also significant with an $\mathrm{I}^{2}$ of 73.066\% $(P<0.001)$ (Fig. 3). There was no significant publication bias $(P=234)$.

Given the efficacy of Etanercept, 516 patients were examined for this drug leading to pooled drug efficacy in $65.2 \%$ (95\%CI: 60.9 to $69.2 \%$ ). The most common side effects of this drug were infections and in some cases drugs intolerability. The documents to systematically assess other biological medications such as Tocilizumab and Rituximab were inadequate, but the mean response rates for these drugs were 59 and 75\%, which required more investigation. The statistical heterogeneity was significant with an $\mathrm{I}^{2}$ of $81.342 \%(P<0.001)$ (Fig. 4). There was also no significant publication bias $(P=0.234)$.

Of DMARDs, only Methotrexate was exclusively evaluated. In this regard, we systematically reviewed 8 studies consisted of 632 patients and could show a pooled response rate of $40.0 \%$ (95\%CI: $36.0 \%$ to 44.2$)$ to Methotrexate. The statistical heterogeneity was also significant with an $\mathrm{I}^{2}$ of $91.314 \%(P<0.001)$ (Fig. 5). There was also a significant publication bias $(P=0.016)$.

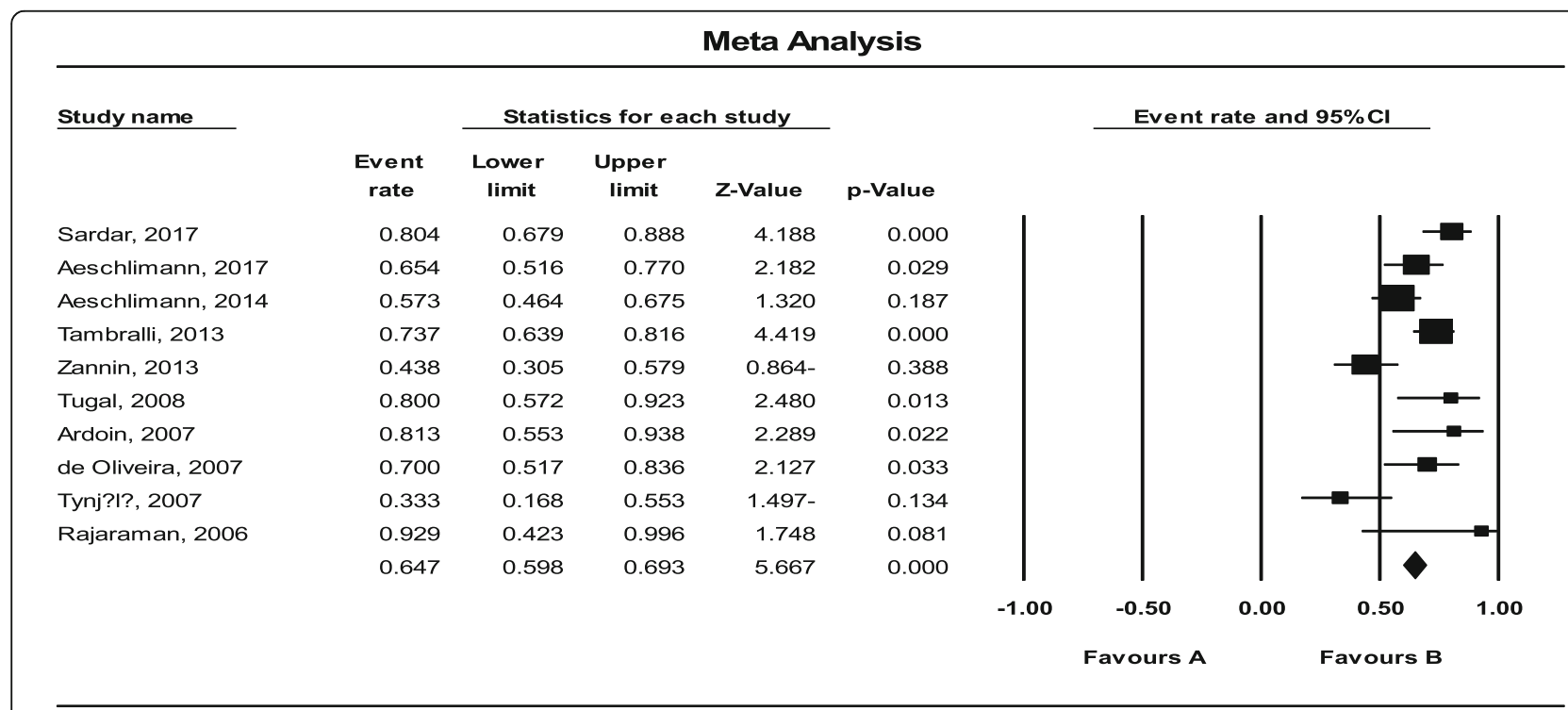

Meta Analysis

Funnel Plot of Standard Error by Logit event rate

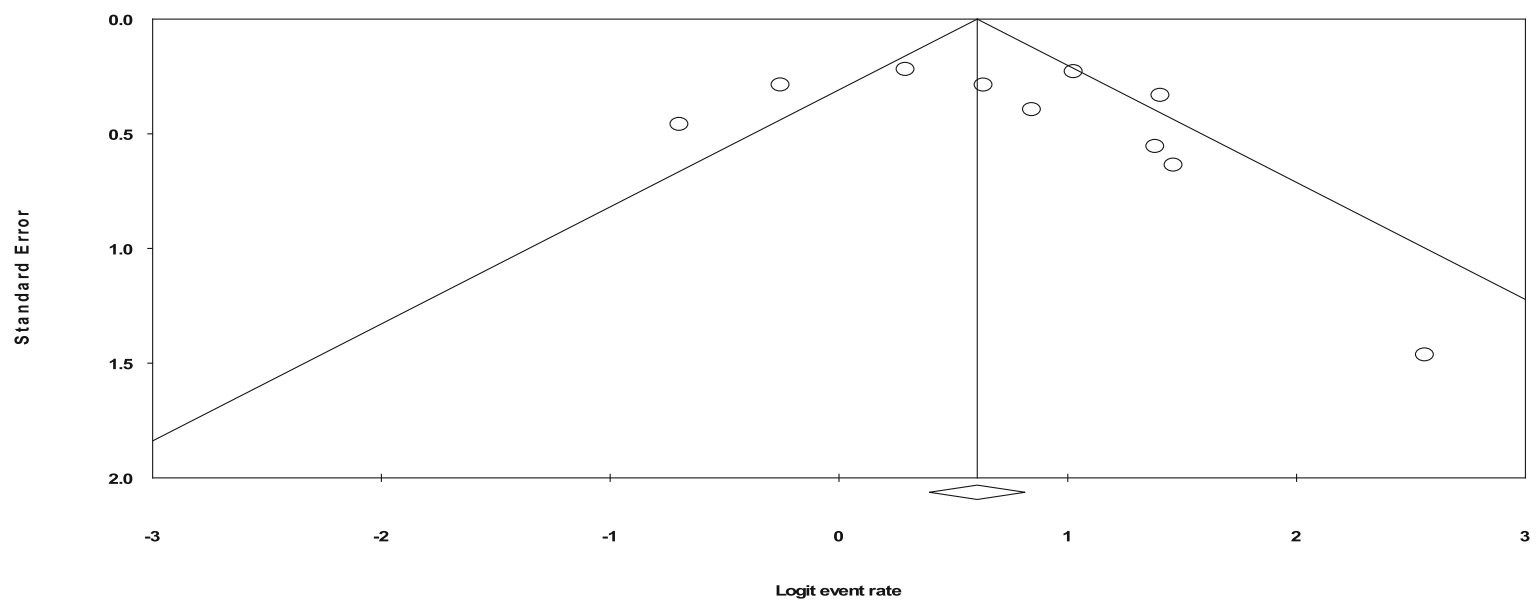

Fig. 3 The efficacy of Infliximab to treat JIA-related uveitis. To determine the efficacy of Infliximab, 476 patients were tested for the medications leading to a pooled response rate of $64.7 \%$ (95\%Cl: 59.8 to 69.3\%). In this regard, the statistical heterogeneity was also significant with an I $^{2}$ of 73.066\% ( $P<0.001)$. There was no significant publication bias $(P=234)$ 


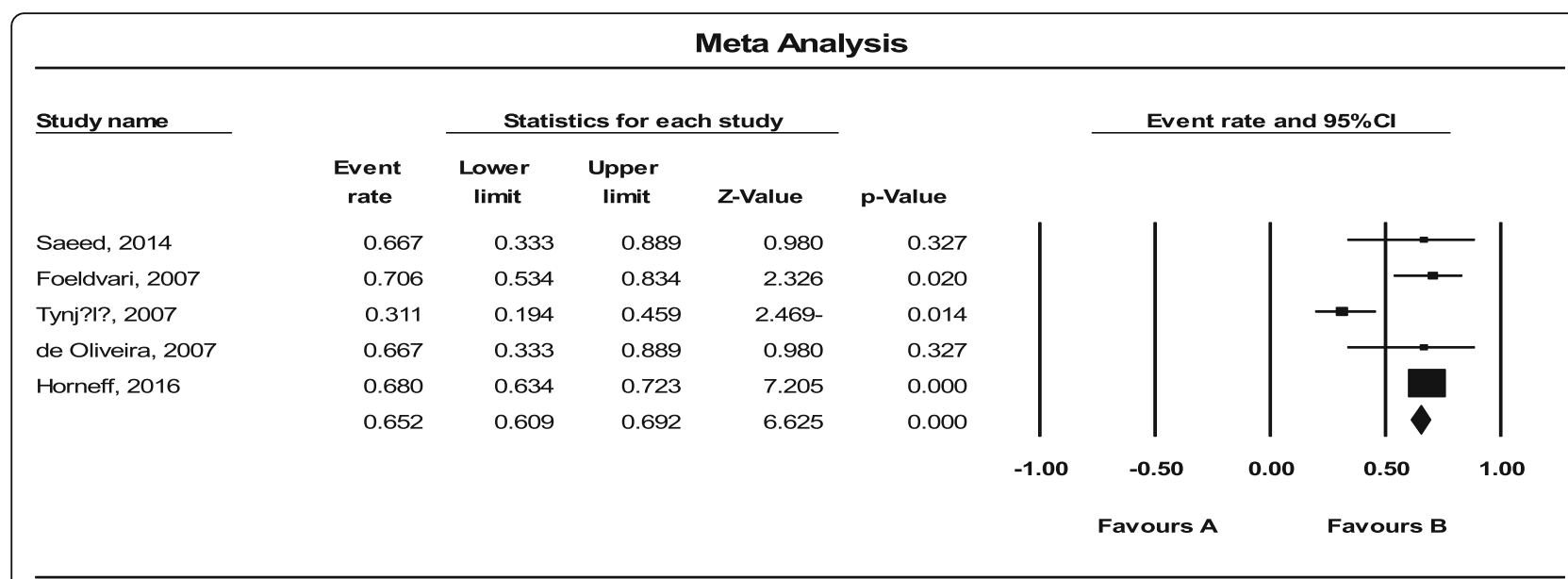

Meta Analysis

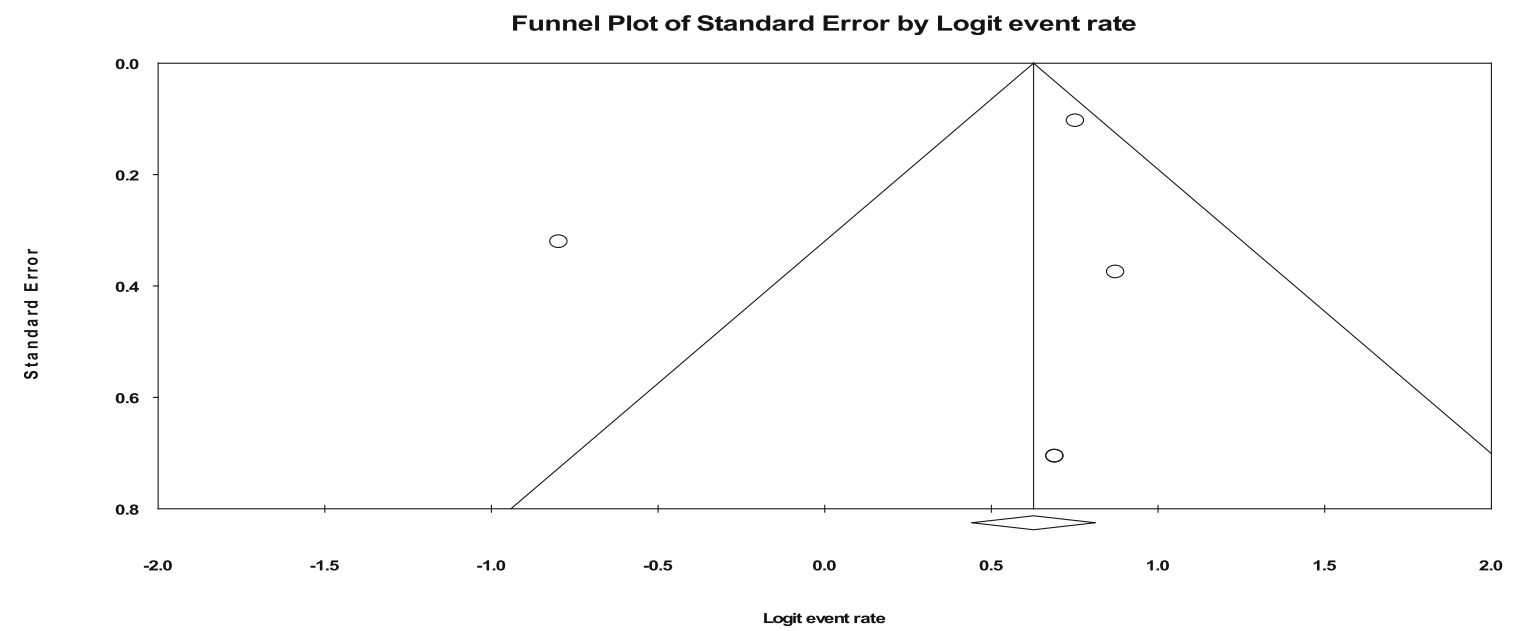

Fig. 4 The efficacy of Etanercept to treat JIA-related uveitis. Respecting the efficacy of Etanercept, 516 patients were examined for this drug leading to pooled drug efficacy in $65.2 \%(95 \% \mathrm{Cl}: 60.9$ to $69.2 \%)$. The statistical heterogeneity was significant with an $I^{2}$ of $81.342 \%(P<0.001)$. There was also no significant publication bias $(P=0.234)$

\section{Discussion}

In our systematic review, we attempted to consider uveitis sourced from all types of pediatric rheumatic diseases. Nevertheless, previous studies mostly focused on children with JIA, which is the most frequent cause for uveitis and the most important rheumatic disease with extra-articular signs. Epidemiologically, owing to differences in the type of studies, the geographical area as well as the different criteria for determining uveitis between 11.6 and 30.0\% $[53,54]$, the prevalence of uveitis associated with JIA was varied. However, our meta-analyses yielded a pooled prevalence of $11.8 \%$ (95\%CI: 11.2 to $12.4 \%$ ) for uveitis following JIA, which is close to the lower limit of the prevalence published in the literature. There seems to be a decreasing incidence of uveitis due to early detection and selection of appropriate, preventive, and therapeutic regimens. In the current systematic review, we also examined potential risk factors for uveitis in pediatric rheumatic disease: female gender, age $<7$ years at the onset of JIA (particularly in girls), oligoarticular subtype of JIA and positive ANA. To put it differently, a combination of both clinical and laboratory markers can be employed to predict the possibility of uveitis in pediatric rheumatic diseases. In the literature, the main indicators for uveitis include female gender, category of JIA, particularly oligoarticular disease, younger age of onset, positive ANA, and HLA-B27 [55, 56]. It should be noted that the role of ethnicity in predicting uveitis remained uncertain. Given the clinical features and complications of childhood rheumatoid uveitis, keratopathy, synechiae, cataract, macular edema, ocular 


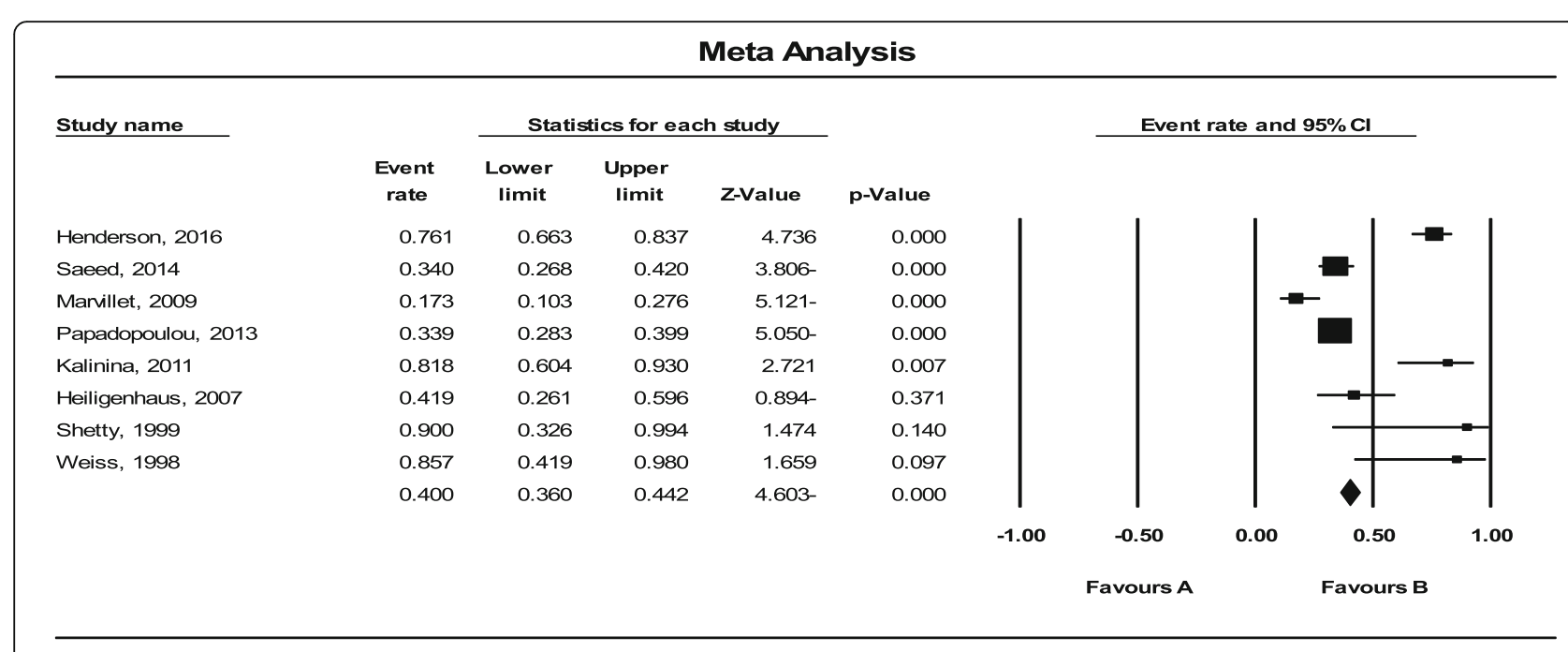

Meta Analysis

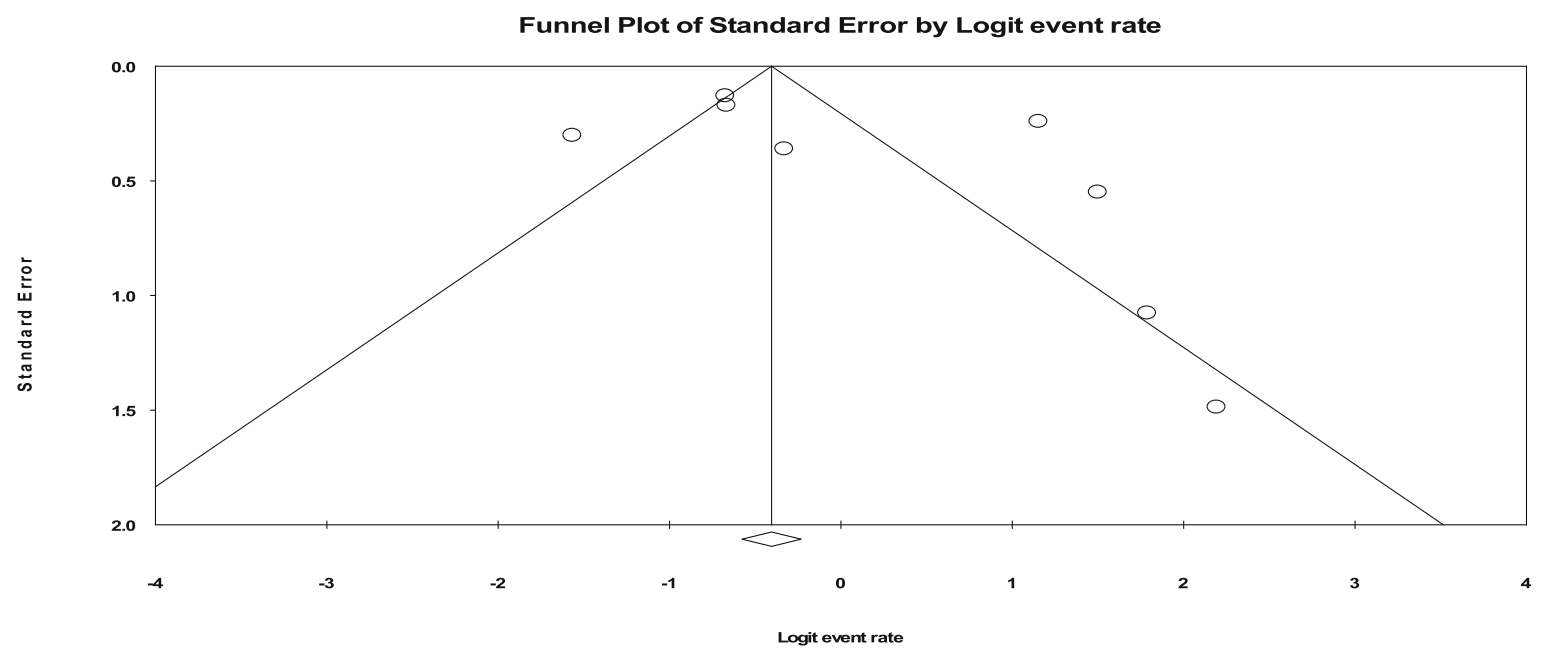

Fig. 5 The efficacy of Methotrexate to treat JIA-related uveitis. To determine the efficacy of Methotrexate, we systematically reviewed 8 studies consisted of 632 patients and could show a pooled response rate of $40.0 \%$ ( $95 \% \mathrm{Cl}: 36.0 \%$ to 44.2$)$ to Methotrexate. The statistical heterogeneity was also significant with an $I^{2}$ of $91.314 \%(P<0.001)$. There was also a significant publication bias $(P=0.016)$

hypertension/glaucoma, and macular fibrosis were the main clinical features of this disease. In general, between one-third and two-third of patients suffer from these manifestations, albeit in cases with delayed diagnosis, severe visual loss and even blindness are expected.

The development of new biological drugs could make JIA-associated uveitis a controllable and early-diagnosed disease over the last decade. Particularly, introduction of TNF-inhibitors could successfully control disease poor prognosis. Our review had the highest concentrations of Adalimumab and Infliximab in the management of uveitis in these patients with a response rate of 68.0 and $64.7 \%$, which appeared to be somewhat acceptable. In this regard, it seems that a combination of biological drugs with other subgroups of drugs such as DMARDs and even glucocorticoids may have been beneficial to achieve a complete recovery under these drugs. The potential side effects and clinical limitations of such drugs should also be considered. Although this review could show higher response rates to some other biologicalbased drugs such as Tocilizumab and Rituximab as 59 and $75 \%$, respectively, a few studies focused on the effectiveness of these drugs; therefore, the clinical efficacy and their potential side effects were unclear. In general, the results demonstrated the high efficacy and safety of biological agents, especially Adalimumab. 
As an important finding, reviewing the studies assessed the efficacy of biological agents reaching the overall responses with a low standard deviation and indicating the correctness of the study design, drug dosages used, and homogeneity of sampling selected for the studies. However, in evaluated studies of DMARDs, especially methotrexate, various responses to medications (33.9 to $85.7 \%$ ) have been reported. In fact, this variety of response rate might be a reason for the low efficacy of these types of drugs for pediatrics. In addition, the necessity for discontinuing drugs and changing them to other drug families may be considered. We could show significant publication bias in those studies focused on DMARDs. The publication bias in medical journals refers to the publication of more articles containing positive conclusions or significant statistical results. This bias suggests that articles containing negative or non-significant statistical results are less likely to be published. The first cause of this bias is that the researchers themselves do not intend to report their negative or non-significant statistical results. Moreover, some organizations that provide funding for medical research may refuse to publish such findings or, at least, delay publication. Thus, the results published on the efficacy of some drugs such as DMARDs on pediatric uveitis might be unreliable, as they require predesign and pre-implementation.

\section{Conclusion}

In this systematic review, we attempted to consider uveitis originated from all types of pediatric rheumatic diseases. However, JIA, especially oligoarticular subtype of disease (positive ANA). is the most frequent cause of uveitis. This study showed the highest efficacy of Adalimumab and Infliximab in the management of uveitis. The efficacy of some drugs such as Tocilizumab and Rituximab showed moderate to high responses, respectively, and few studies focused on the effectiveness of these drugs; therefore, the clinical efficacy and their potential side effects were unclear. In general, the results summarize the efficacy and safety of biological agents, particularly Adalimumab. In the evaluated studies of DMARDs, especially methotrexate, mild to moderate responses have been reported.

\footnotetext{
Abbreviations

ANA: Antinuclear antibody; Cl: Confidence Interval; DMARDS: Disease Modifying Anti-Rheumatic Drugs; HLA: Human Leukocyte Antigen; JIA: Juvenile Idiopathic Arthritis; OR: Odds Ratio; PRISMA-P: Preferred Reporting Items for Systematic review and Meta-Analysis Protocols; SLE: Systemic Lupus Erythematosus
}

\section{Acknowledgements}

The authors would like to thank the pediatric department at Mofid Children's Hospital, Tehran, Iran, for their contributions.

\section{Authors' contributions}

Project conception: RS. Formulation of PICO and the first draft of the manuscript: MJ, VJP. Analysis and critical review of recommendations: All authors read and approved the final manuscript: RS, KR.

\section{Funding}

The project received no direct funding.

Availability of data and materials

The data are available on request to the corresponding author.

Ethics approval and consent to participate

Not applicable.

\section{Consent for publication}

Not applicable. No patient data were included in this work.

\section{Competing interests}

The authors declare they have no competing interests.

\section{Author details}

'Department of Pediatric Rheumatology, Imam Hossein Children's Hospital. Isfahan University of Medical Sciences, Isfahan, Iran. ${ }^{2}$ Child Growth and Development Research Center, Research Institute for Primordial prevention of non-communicable Disease, Isfahan University of Medical Sciences, Isfahan, Iran. ${ }^{3}$ Department of Pediatric Rheumatology, Shahid Beheshti University of Medical Sciences, Tehran, Iran. ${ }^{4}$ Negah Specialty Ophthalmic Research Center, Shahid Beheshti University of Medical Sciences, Tehran, Iran.

Received: 26 October 2019 Accepted: 28 January 2020

Published online: 04 February 2020

\section{References}

1. Cunningham ET Jr, Smith JR, Tugal-Tutkun I, Rothova A, Zierhut M. Uveitis in Children and Adolescents. Ocullmmunol Inflamm. 2016;24(4):365-71.

2. Majumder PD, Biswas J. Pediatric uveitis: An update. Oman J Ophthalmol. 2013;6(3):140-50.

3. Sood AB, Angeles-Han ST. An Update on Treatment of Pediatric Chronic Non-Infectious Uveitis. CurrTreatm Opt Rheumatol. 2017;3(1):1-16.

4. Sharma SM, Dick AD, Ramanan AV. Non-infectious pediatric uveitis: an update on immunomodulatory management. Paediatr Drugs. 2009;11(4):229-41.

5. Shamseer L, Moher D, Clarke M, Ghersi D, Liberati A, Petticrew M, Shekelle P, Stewart L, PRISMA-P Group. Preferred reporting items for systematic review and meta-analysis protocols (PRISMA-P) 2015: elaboration and explanation. BMJ. 2015;349(jan02 1):g7647

6. Zeng X, Zhang Y, Kwong JS, Zhang C, Li S, Sun F, Niu Y, Du L. The methodological quality assessment tools for preclinical and clinical studies, systematic review and meta-analysis, and clinical practice guideline: a systematic review. J Evid Based Med. 2015;8(1):2-10.

7. Nordal E, Rypdal V, Christoffersen T, Aalto K, Berntson L, Fasth A, Herlin T, Nielsen S, Peltoniemi S, Straume B, Zak M, Rygg M, Nordic Study Group of Pediatric Rheumatology (NoSPeR). Incidence and predictors of Uveitis in juvenile idiopathic arthritis in a Nordic long-term cohort study. Pediatr Rheumatol Online J. 2017;15(1):66.

8. Sardar E, Dusser P, Rousseau A, Bodaghi B, Labetoulle M, Koné-Paut I. Retrospective Study Evaluating Treatment Decisions and Outcomes of Childhood Uveitis Not Associated with Juvenile Idiopathic Arthritis. J Pediatr. 2017;186:131137.e1. https://doi.org/10.1016/j.jpeds.2017.03.052 Epub 2017 Apr 27.

9. Kahwage PP, Ferriani MP, Furtado JM, de Carvalho LM, Pileggi GS, Gomes FH, Terreri MT, Magalhães CS, Pereira RM, Sacchetti SB, Marini R, Bonfá E, Silva CA, Ferriani VP. Uveitis in childhood-onset systemic lupus erythematosus patients: a multicenter survey. ClinRheumatol. 2017;36(3): 547-53. https://doi.org/10.1007/s10067-016-3534-0 Epub 2017 Jan 9.

10. Cecchin V, Sperotto F, Balzarin M, Vittadello F, Martini G, Zulian F. Joint hypermobility and oligoarticular juvenile idiopathic arthritis: What relationship? Paediatr Child Health. 2017;53(4):374-7. https://doi.org/10. 1111/jpc.13450 Epub 2017 Jan 4.

11. Angeles-Han ST, McCracken C, Yeh S, Jenkins K, Stryker D, Rouster-Stevens K, Vogler LB, Lambert SR, Drews-Botsch C, Prahalad S. Characteristics of a cohort of children with Juvenile Idiopathic Arthritis and JIA-associated 
Uveitis. Pediatr Rheumatol Online J. 2015;13:19. https://doi.org/10.1186/ s12969-015-0018-8.

12. Angeles-Han ST, Pelajo CF, Vogler LB, Rouster-Stevens K, Kennedy C, Ponder L, McCracken C, Lopez-Benitez J, Drews-Botsch C, Prahalad S, CARRA Registry Investigators. Risk markers of juvenile idiopathic arthritis-associated uveitis in the Childhood Arthritis and Rheumatology Research Alliance (CARRA) Registry. J Rheumatol. 2013;40(12):2088-96. https://doi.org/10.3899/ jrheum.130302 Epub 2013 Nov 1.

13. Clarke LA, Guex-Crosier Y, Hofer M. Epidemiology of uveitis in children over a 10-year period. ClinExpRheumatol. 2013;31(4):633-7 Epub 2013 Feb 22.

14. Shen CC, Yeh KW, Ou LS, Yao TC, Chen LC, Huang JL. Clinical features of children with juvenile idiopathic arthritis using the ILAR classification criteria: a community-based cohort study in Taiwan. JMicrobiollmmunol Infect. 2013; 46(4):288-94. https://doi.org/10.1016/j.jmii.2012.03.006 Epub 2012 Jun 21.

15. Reininga JK, Los LI, Wulffraat NM, Armbrust W. The evaluation of uveitis in juvenile idiopathic arthritis (JIA) patients: are current ophthalmologic screening guidelines adequate? ClinExpRheumatol. 2008;26(2):367-72.

16. Grassi A, Corona F, Casellato A, Carnelli V, Bardare M. Prevalence and outcome of juvenile idiopathic arthritis-associated uveitis and relation to articular disease. JRheumatol. 2007;34(5):1139-45 Epub 2007 Mar 1.

17. Heiligenhaus A, Niewerth M, Mingels A, Ganser G, Thon A, Pleyer U, Greiner K, Minden K. Epidemiology of uveitis in juvenile idiopathic arthritis from a national paediatric rheumatologic and ophthalmologic database. KlinMonblAugenheilkd. 2005;222(12):993-1001.

18. Chalom EC, Goldsmith DP, Koehler MA, Bittar B, Rose CD, Ostrov BE, Keenan GF. Prevalence and outcome of uveitis in a regional cohort of patients with juvenile rheumatoid arthritis. JRheumatol. 1997;24(10):2031-4.

19. Akduman L, Kaplan HJ, Tychsen L. Prevalence of uveitis in an outpatient juvenile arthritis clinic: onset of uveitis more than a decade after onset of arthritis.JPediatrOphthalmol. Strabismus. 1997;34(2):101-6.

20. Correll CK, Bullock DR, Cafferty RM, Vehe RK. Safety of weekly adalimumab in the treatment of juvenile idiopathic arthritis and pediatric chronic uveitis. ClinRheumatol. 2017;37(2):549. https://doi.org/10.1007/s10067-017-3890-4 [Epub ahead of print].

21. Horneff G, Klein A, Klotsche J, Minden K, Huppertz HI, Weller-Heinemann F, Kuemmerle-Deschner J, Haas JP, Hospach A. Comparison of treatment response, remission rate and drug adherence in polyarticular juvenile idiopathic arthritis patients treated with etanercept, adalimumab or tocilizumab. Arthritis Res Ther. 2016;18(1):272.

22. Castiblanco C, Meese H, Foster CS. Treatment of pediatric uveitis with adalimumab: the MERSI experience. J AAPOS. 2016;20(2):145-7. https://doi. org/10.1016/j.jaapos.2015.12.006.

23. Henderson LA, Zurakowski D, Angeles-Han ST, Lasky A, Rabinovich CE. Lo MS; Childhood Arthritis and Rheumatology Research Alliance (CARRA) Registry Investigators Medication use in juvenile uveitis patients enrolled in the Childhood Arthritis and Rheumatology Research Alliance Registry. PediatrRheumatol Online J. 2016;14(1):9. https://doi.org/10.1186/s12969-0160069-5.

24. Klotsche J, Niewerth M, Haas JP, Huppertz HI, Zink A, Horneff G, Minden K. Long-term safety of etanercept and adalimumabcompared to methotrexate in patients with juvenile idiopathic arthritis (JIA). Ann Rheum Dis. 2016;75(5): 855-61. https://doi.org/10.1136/annrheumdis-annrheumdis-2014-206747 Epub 2015 Apr 29.

25. Schmeling H, Minden K, Foeldvari I, Ganser G, Hospach T, Horneff G. Efficacy and safety of adalimumab as the first and second biologic agent in juvenile idiopathic arthritis: the German Biologics JIA Registry. ArthritisRheumatol. 2014:66(9):2580-9. https://doi.org/10.1002/art.38741.

26. García-De-Vicuña C, Díaz-Llopis M, Salom D, Bou R, Díaz-Cascajosa J, Cordero-Coma M, Ortega G, Ortego-Centeno N, Suarez-De-Figueroa M, Cruz-Martínez J, Fonollosa A, Blanco R, García-Aparicio ÁM, Benítez-DelCastillo JM, Antón J. Usefulness of adalimumab in the treatment of refractory uveitis associated with juvenile idiopathic arthritis. MediatorsInflamm. 2013;2013:560632. https://doi.org/10.1155/2013/560632 Epub 2013 Dec 30.

27. Lerman MA, Burnham JM, Chang PY, Daniel E, Foster CS, Hennessy S, Jabs DA, Joffe MM, Kaçmaz RO, Levy-Clarke GA, Mills MD, Nussenblatt RB, Rosenbaum JT, Suhler EB, Thorne JE, Kempen JH. Response of pediatric uveitis to tumor necrosis factor-a inhibitors. J Rheumatol. 2013;40(8):1394403. https://doi.org/10.3899/jrheum.121180 Epub 2013 Jul 1.

28. Simonini G, Taddio A, Cattalini M, Caputo R, de Libero C, Parentin F, Pagnini I, Lepore L, Cimaz R. Superior efficacy of Adalimumab in treating childhood refractory chronic uveitis when used as first biologic modifier drug: Adalimumab as starting anti-TNF-a therapy in childhood chronic uveitis. Pediatr Rheumatol Online J. 2013;11:16. https://doi.org/10.1186/1546-009611-16 eCollection 2013.

29. Zannin ME, Birolo C, Gerloni VM, Miserocchi E, Pontikaki I, Paroli MP, Bracaglia C, Shardlow A, Parentin F, Cimaz R, Simonini G, Falcini F, Corona F, Viola S, De Marco R, Breda L, La Torre F, Vittadello F, Martini G, Zulian F. Safety and efficacy of infliximab and adalimumab for refractory uveitis in juvenile idiopathic arthritis: 1-year followup data from the Italian Registry. J Rheumatol. 2013;40(1):74-9. https://doi.org/10.3899/jrheum.120583 Epub 2012 Nov 1.

30. Trachana M, Pratsidou-Gertsi P, Pardalos G, Kozeis N, Badouraki M, KanakoudiTsakalidou F. Safety and efficacy of adalimumab treatment in Greek children with juvenile idiopathic arthritis. Scand J Rheumatol. 2011;40(2):101-7. https:// doi.org/10.3109/03009742.2010.517546 Epub 2010 Nov 25.

31. Tynjälä P, Kotaniemi $K$, Lindahl P, Latva K, Aalto K, Honkanen V, Lahdenne P. Adalimumab in juvenile idiopathic arthritis-associated chronic anterior uveitis. Rheumatology (Oxford). 2008;47(3):339-44. https://doi.org/10.1093/ rheumatology/kem356 Epub 2008 Jan 31.

32. Gallagher M, Quinones K, Cervantes-Castañeda RA, Yilmaz T, Foster CS. Biological response modifier therapy for refractory childhood uveitis. $\mathrm{Br} J$ Ophthalmol. 2007;91(10):1341-4 Epub 2007 Jun 7.

33. Vazquez-Cobian LB, Flynn T, Lehman TJ. Adalimumab therapy for childhood uveitis. J Pediatr. 2006;149(4):572-5.

34. Aeschlimann FA, Angst F, Hofer KD, Cannizzaro Schneider E, SchroederKohler S, Lauener R, van der Kleij D, Rispens T, Saurenmann RK. Prevalence of Anti-infliximab Antibodies and Their Associated Co-factors in Children with Refractory Arthritis and/or Uveitis: A Retrospective Longitudinal Cohort Study. J Rheumatol. 2017;44(3):334-41. https://doi.org/10.3899/jrheum. 160072 Epub 2017 Jan 15.

35. Aeschlimann FA, Hofer KD, Cannizzaro Schneider E, Schroeder S, Lauener R, Saurenmann RK. Infliximab in pediatric rheumatology patients: a retrospective analysis of infusion reactions and severe adverse events during 2246 infusions over 12 years. Rheumatol. 2014;41(7):1409-15. https:// doi.org/10.3899/jrheum.131231 Epub 2014 May 15.

36. Tambralli A, Beukelman T, Weiser P, Atkinson TP, Cron RQ, Stoll ML. High doses of infliximab in the management of juvenile idiopathic arthritis. JRheumatol. 2013;40(10):1749-55. https://doi.org/10.3899/jrheum.130133 Epub 2013 Aug 15.

37. Tugal-Tutkun I, Ayranci O, Kasapcopur O, Kir N. Retrospective analysis of children with uveitistreated with infliximab. J AAPOS. 2008;12(6):611-3. https://doi.org/10.1016/j.jaapos.2008.08.007 Epub 2008 Oct 19.

38. Ardoin SP, Kredich D, Rabinovich E, Schanberg LE, Jaffe GJ. Infliximab to treat chronic noninfectious uveitis in children: retrospective case series with longterm follow-up. Am J Ophthalmol. 2007;144(6):844-9 Epub 2007 Oct 22.

39. de Oliveira SK, de Almeida RG, Fonseca AR, Rodrigues MC, Sztajnbok F, Diniz C. Indications and adverse events with the use of anti-TNFalpha agents in pediatric rheumatology: experience of a single center. Acta Reumatol Port. 2007;32(2):139.

40. Tynjälä P, Lindahl P, Honkanen V, Lahdenne P, Kotaniemi K. Infliximab and etanercept in the treatment of chronic uveitis associated with refractory juvenile idiopathic arthritis. Ann Rheum Dis. 2007;66(4):548-50 Epub 2006 Oct 26.

41. Rajaraman RT, Kimura Y, Li S, Haines K, Chu DS. Retrospective case review of pediatric patients with uveitis treated with infliximab. Ophthalmology. 2006; 113(2):308-14 Epub 2006 Jan 10

42. Saeed MU, Raza SH, Goyal S, Cleary G, Newman WD, Chandna A. Etanercept in methotrexate-resistant JIA-related uveitis. Semin Ophthalmol. 2014;29(1): 1-3. https://doi.org/10.3109/08820538.2013.839802 Epub 2013 Oct 31.

43. Foeldvari I, Nielsen S, Kümmerle-Deschner J, Espada G, Horneff G, Bica B, Olivieri AN, Wierk A, Saurenmann RK. Tumor necrosis factor-alpha blocker in treatment of juvenile idiopathic arthritis-associated uveitisrefractory to second-line agents: results of a multinational survey. J Rheumatol. 2007; 34(5):1146-50 Epub 2007 Mar 1.

44. Quesada-Masachs E, Caballero CM. Subcutaneous Tocilizumab May Be Less Effective than Intravenous Tocilizumab in the Treatment of Juvenile Idiopathic Arthritis-associated Uveitis. J Rheumatol. 2017;44(2):260-1. https:// doi.org/10.3899/jheum.160908.

45. Tappeiner C, Mesquida M, Adán A, Anton J, Ramanan AV, Carreno E, Mackensen F, Kotaniemi $\mathrm{K}$, de Boer JH, Bou R, de Vicuña CG, Heiligenhaus A. Evidence for Tocilizumab as a Treatment Option in Refractory Uveitis 
Associated with Juvenile Idiopathic Arthritis. JRheumatol. 2016;43(12):2183-8 Epub 2016 Sep 15.

46. Miserocchi E, Modorati G, Berchicci L, Pontikaki I, Meroni P, Gerloni V. Longterm treatment with rituximab in severe juvenile idiopathic arthritisassociated uveitis. Br J Ophthalmol. 2016;100(6):782-6. https://doi.org/10. 1136/bjophthalmol-2015-306790 Epub 2015 Sep 22.

47. Marvillet I, Terrada C, Quartier P, Quoc EB, Bodaghi B, Prieur AM. Ocular threat in juvenile idiopathic arthritis. Joint Bone Spine. 2009;76(4):383-8. https://doi.org/10.1016/j.jbspin.2008.10.015 Epub 2009 Jun 12.

48. Papadopoulou C, Kostik M, Böhm M, Nieto-Gonzalez JC, GonzalezFernandez MI, Pistorio A, Martini A, Ravelli A. Methotrexate therapy may prevent the onset of uveitis in juvenile idiopathic arthritis. J Pediatr. 2013; 163(3):879-84. https://doi.org/10.1016/j.jpeds.2013.03.047 Epub 2013 May 9

49. KalininaAyuso V, van de Winkel EL, Rothova A, de Boer JH. Relapse rate of uveitis post-methotrexate treatment in juvenile idiopathic arthritis. Am J Ophthalmol. 2011;151(2):217-22. https://doi.org/10.1016/j.ajo.2010.08.021 Epub 2010 Dec 9.

50. Heiligenhaus A, Mingels A, Heinz C, Ganser G. Methotrexate for uveitis associated with juvenile idiopathic arthritis: value and requirement for additional anti-inflammatory medication. Eur J Ophthalmol. 2007;17(5):743-8.

51. Shetty AK, Zganjar BE, Ellis GS Jr, Ludwig $H$, Gedalia A. Low-dose methotrexate in the treatment of severe juvenile rheumatoid arthritis and sarcoidiritis. J Pediatr Ophthalmol Strabismus. 1999;36(3):125-8.

52. Weiss AH, Wallace CA, Sherry DD. Methotrexate for resistant chronic uveitis in children with juvenile rheumatoid arthritis. J Pediatr. 1998;133(2):266-8.

53. Sen ES, Morgan MJ, MacLeod R, Strike H, Hinchcliffe A, Dick AD, Muthusamy B, Ramanan AV. Cross sectional, qualitative thematic analysis of patient perspectives of disease impact in juvenile idiopathic arthritis-associated uveitis. Pediatr Rheumatol Online J. 2017;15(1):58.

54. Cosickic A, Halilbasic M, Selimovic A, Avdagic H. Uveitis Associated with Juvenile Idiopathic Arthritis, our Observations. Mediev Archaeol. 2017;71(1):52-5.

55. Walscheid K, Hennig M, Heinz C, Wasmuth S, Busch M, Bauer D, Dietzel M, Deeg CA, Heiligenhaus A. Correlation between disease severity and presence of ocular autoantibodies in juvenile idiopathic arthritis-associated uveitis. Invest Ophthalmol Vis Sci. 2014;55(6):3447-53.

56. Tugal-Tutkun I, Quartier P, Bodaghi B. Disease of the year: juvenile idiopathic arthritis-associated uveitis--classification and diagnostic approach. Ocul Immunol Inflamm. 2014;22(1):56-63.

\section{Publisher's Note}

Springer Nature remains neutral with regard to jurisdictional claims in published maps and institutional affiliations.

Ready to submit your research? Choose BMC and benefit from:

- fast, convenient online submission

- thorough peer review by experienced researchers in your field

- rapid publication on acceptance

- support for research data, including large and complex data types

- gold Open Access which fosters wider collaboration and increased citations

- maximum visibility for your research: over $100 \mathrm{M}$ website views per year

At BMC, research is always in progress.

Learn more biomedcentral.com/submissions 